P140 (continued)

meeting the goal. They were nearer the HP2020 goal for total daily calorie intake provided by added sugars (13.6\%) with $42.8 \%$ meeting the target, twice that of Black children (21.4\%).

Conclusions and Implications: Although nutrition lessons support eating vegetables, reducing fast food consumption would have a greater impact on improving children's diets. Incorporating innovative education and PSE approaches that address fast food can enhance nutrition education interventions in low-income communities to improve diet and reduce overweight among low-income CalFresh/SNAP children.

Funding: Supplemental Nutrition Assistance Program.

\section{P141 Shaping a SNAP-Ed Parent Website to Better Support Behavior Change}

Zena Edwards, MS, RD, zena_edwards@wsu.edu, Washington State University Extension, 1102 Creekwood Court, SE, Apartment D, Olympia, WA 98501;

E. Weintraub Austin, PhD, Washington State University Murrow Center for Media and Health Promotion; B. E. Pinkleton, PhD; J. Shultz, PhD; K. Manenica, MS, Washington State University Extension

Objective: We investigated preferences of Supplemental Nutrition Assistance Program Education (SNAP-Ed) parents regarding content and design of a website to support the adoption of the SNAP-Ed behavioral objectives.

Theory, Prior Research, Rationale: Web-based nutrition education interventions can be a cost-effective method of improving the likelihood that individuals will adopt healthy behaviors. Research shows that website characteristics determine the likelihood of use by SNAP participants.

Study Design, Setting, Participants, and Intervention: Six 90-minute focus groups were conducted with parents(5-7 per group; $n=37$ ) recruited from four SNAP-Ed locations in Washington State. Participants spent 15 minutes exploring a set of 4 preloaded food and nutrition related websites provided on a wireless tablet.

Outcome, Measures and Analysis: Participants then shared their opinions about the websites and provided suggestions for website design. Sessions were tape-recorded, transcribed, and analyzed using emergent themes analysis.

Results: SNAP-Ed parents are interested in using websites for making meals from "what's on-hand,"quick family meals, healthier snacks; as well as gaining skills in food shopping, meal planning and cooking. Revealing insights about visual appeal, ease of navigation, usefulness of information, perceived credibility, and perceived relevance and benefits of information will be shared. More research is needed about perceived website credibility. Participants had negative reactions to on-line lessons with certificates of completion, Twitter, and blogs, and reservations about registering or subscribing.
Conclusions and Implications: Results from this project are being utilized for the initial development of a WSU Extension SNAP-Ed Food \$ense client-centered website. Continued and ongoing testing will need to be done to make sure the final product reflects SNAP-Ed parents' needs regarding content, credibility, usefulness and usability.

Funding: Supplemental Nutrition Assistance Program Education.

\section{P142 What Is the Distribution of Nutrition Education Program in Public Elementary Schools?: The NYC Experience}

Kathleen J. Porter, MS, RD, kjp2103@tc.columbia.edu, Teachers College Columbia University, 525 West 120th Street, Box 137, New York, NY 10027; P. A. Koch, EdD, RD; I. R. Contento, $P h D$

Objective: To describe the distribution of Nutrition Education Program from Outside Sources (NEPOS) in NYC public elementary schools.

Theory, Prior Research, Rationale: School-based nutrition education programs are increasing popular. Yet, little is known about how many, what types, and how they are distributed among schools.

Study Design, Setting, Participants, and Intervention: Eligible NEPOS were identified using a snowball approach. Program staff completed an online survey about program characteristics and provided a list of elementary schools that implemented their program in school year 2011-2012. A database of elementary schools in the boroughs of Brooklyn, Manhattan, Queens was created, including publically available descriptive data.

Outcome, Measures and Analysis: Number of programs for each school were tallied. Ranges and frequencies of NEPOS characteristics were calculated. Paired T-tests compared schools with programs to those without programs.

Results: There was a total of 41 NEPOS. Programs ranged from 1 lesson to more than 25 lessons. Most programs reported addressing academic standards (71.4\%). Of the 614 schools, 226 (36.8\%) had 1 or more programs, with 78 having more than 2 . Schools with and without programs were similar regarding percent of students eligible for free/reduced lunch ( $76 \%$ both); identifying as African American (33.5\% and 37\%); identifying as Caucasian (14.5\% and $15.3 \%)$; and at or above grade level on state tests. Schools with NEPOS had a greater percentage of Hispanic students $(37.4 \%$ vs. $31.2 \%$ $\mathrm{p}=.005$ ).

Conclusions and Implications: There are a variety of NEPOS available, yet a high percentage of schools still have no programs. These findings could help foster a more coordinated approach to further disseminate NEPOS.

Funding: None. 